\title{
Spatial Analyses of the 2011 Joplin Tornado Mortality: Deaths by Interpolated Damage Zones and Location of Victims
}

\author{
BIMAL KANTI PAUL \\ Department of Geography, Kansas State University, Manhattan, Kansas \\ MITCHEL STIMERS \\ Department of Natural and Physical Sciences, Cloud County Community College, Junction City, Kansas
}

(Manuscript received 26 February 2013, in final form 8 January 2014)

\begin{abstract}
On 22 May 2011, a massive tornado tore through a densely populated section of Joplin, Missouri, killing 162 people. The EF5 tornado was the deadliest single tornado to occur in the United States since modern record keeping began in 1950, surpassing the tornado of 8 June 1953, which claimed 116 lives in Flint, Michigan. The Joplin tornado death toll was also far higher than the average annual number of deaths caused by tornadoes in the United States between 2000 and 2011. This study analyzed Joplin deaths by damage zone and place of death. Tabular data collected primarily from secondary sources revealed the number of deaths and death rates differ significantly by zone of destruction. The central zone (labeled as "catastrophic") had the most deaths, with the number decreasing systematically in both directions from the center of that zone. The results of this study further show that more people died in nonresidential buildings in Joplin than is usual in a U.S. tornado event, calling into question how well such structures protect occupants. Finally, the lack of basements in residential and other structures most likely contributed greatly to the high death toll, although the degree remains uncertain. Several recommendations are offered to reduce future U.S. tornado fatalities.
\end{abstract}

\section{Introduction}

The number of deaths and the extent of destruction caused by tornadoes are directly associated with their track length or path and their magnitude (Paul 2011; Simmons and Sutter 2011, 2012). In the United States, tornado paths typically range from less than a mile up to $100 \mathrm{mi}(150 \mathrm{~km})$. The paths of long-track tornadoes differ in strength or magnitude, which is now measured on the Enhanced Fujita (EF) scale, along their paths. ${ }^{1}$

\footnotetext{
${ }^{1}$ From 1971 through 2007, tornado magnitude or intensity was measured on the Fujita scale (F scale), introduced by Theodore Fujita in 1971, and it ranged from F0 through F5. On 1 February 2007, the EF scale replaced the F scale. The EF scale has the same basic design as the original scale, with six categories from 0 to 5 representing increasing degrees of damage (Paul 2011). It should be noted that EF and F scales are damage scales, not, strictly speaking, intensity measures, even though we use them to control for magnitude (Wurman et al. 2007).
}

Corresponding author address: Bimal Kanti Paul, Department of Geography, 118 Seaton Hall, Kansas State University, Manhattan, KS 66506.

E-mail: bkp@ksu.edu
Irrespective of lengths, tornado tracks are widely considered linear, like rivers and roads, and thus are represented by a line, usually running southwest to northeast (Suckling and Ashley 2006). Although length is a dominant distinguishing feature, the width of tornado paths also varies, ranging from a few feet to a mile or more. One of the widest tornadoes was the Hallam, Nebraska, event that occurred on 22 May 2004. At one point, the funnel was $2.5 \mathrm{mi}(4 \mathrm{~km})$ wide. In the United States, on average, tornadoes are approximately $500 \mathrm{ft}(150 \mathrm{~m})$ across (Lyons 1997).

The strength of tornadoes varies not only linearly or horizontally, but also within or across the path. The EF scale applied along the tornado path should most accurately represent the event's magnitude at the central zone of the path. This zone generally sustains the most damage and is the location of the most deaths. The strength or intensity of tornadoes and hence the extent of damage and death usually decreases toward outer zones. Empirical studies (e.g., Turner and Hacker 2011; Simmons et al.2012) claim that structures on the edge of a tornado suffer the least damage; these studies further suggest that if the central zone sees EF5 damage, then 


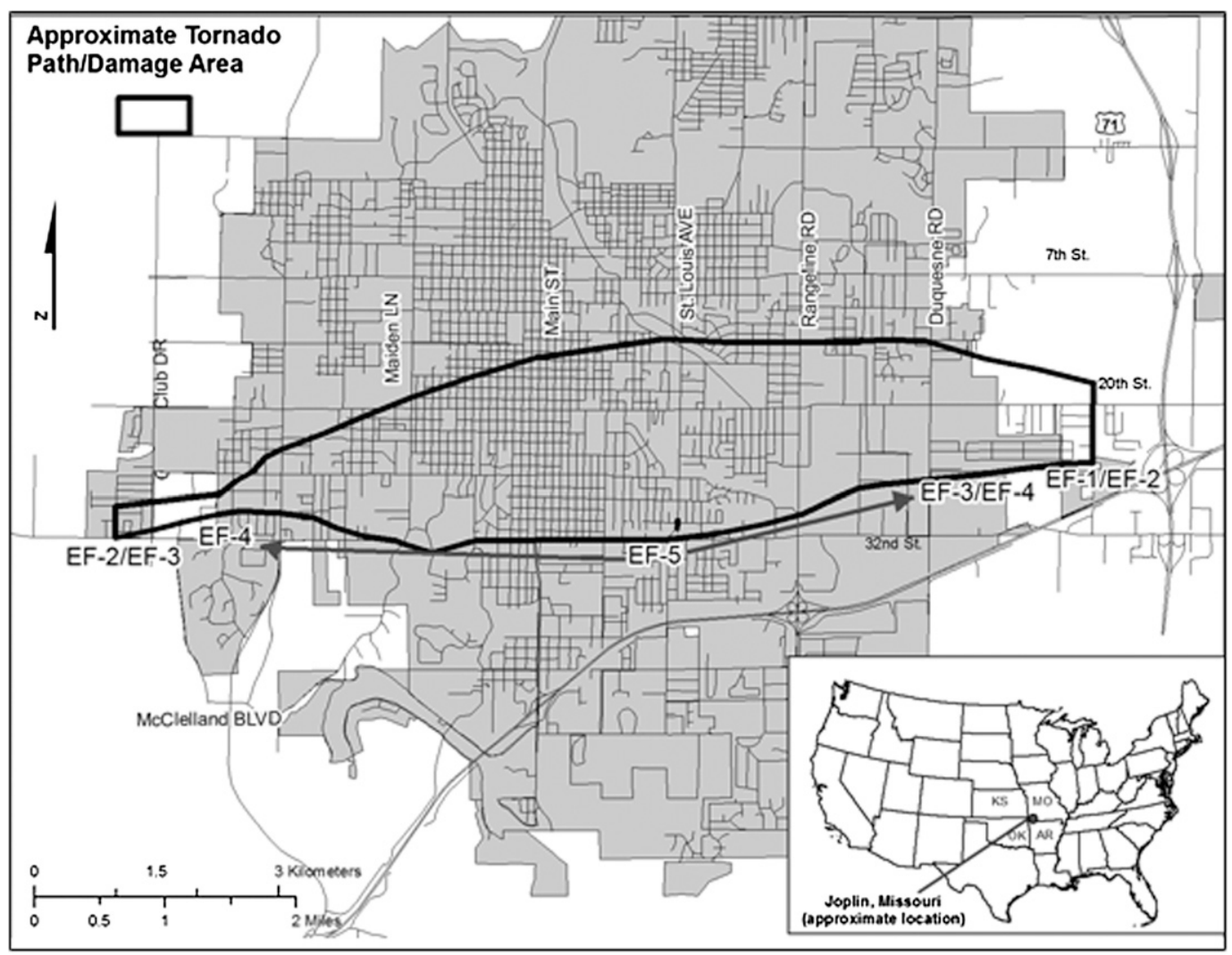

FIG. 1. Tornado damage path in Joplin.

structures on the edge suffer only EF0 or EF1 damage. This is primarily because of variation in wind speed across the tornado track (see Wurman et al. 2007).

The area across the tornado path or width of the tornado track that sustains tornado damage is termed the "damage zone," which can be further divided based on the extent of the damage. Unfortunately, damage zones of tornado paths are widely ignored by hazard researchers. As a result, tornado deaths are exclusively studied in relation to EF scale measured along the horizontal path. One notable exception is the study of Curtis and Fagan (2013), who, using spatial video, analyzed 135 of the 162 Joplin tornado fatalities along the spatial video path by type of location and age category. They also analyzed fatalities in terms of the Tornado Injury Scale (TIS) and four damaged areas derived using the spatial video system.

The objective of this study is to examine the deaths caused by the 2011 Joplin tornado by damage zones. This examination also includes gender and age analysis of the tornado victims. We hypothesized that the number of deaths would decrease outward from the central zone. Attempts are also made to study the locations where Joplin tornado victims died along with fatalities by structure type and damage zone.
The next section of this paper provides a brief description of the 2011 Joplin tornado, followed by an overview of tornado fatalities in the United States. Next, the data collection procedure, the results, and conclusions of this study are presented.

\section{The 2011 Joplin, Missouri, tornado}

A deadly tornado touched down at the southwest edge of the city of Joplin, Missouri, on the evening of 22 May 2011 (Fig. 1). It was approximately a half-mile wide when it hit the city near Schifferdecker Avenue; at this point, it was rated EF2 to EF3 (NWS 2011). It grew to three-quarters of a mile wide between 26th and East 20th Street. The forward speed of the tornado through most of Joplin was less than $20 \mathrm{mi}(30 \mathrm{~km}) \mathrm{h}^{-1}$ (Turner and Hacker 2011). Of the total track of $22.1 \mathrm{mi}(35.6 \mathrm{~km})$, the tornado traveled at least a 6-mi-long path across a densely populated part of Joplin with winds of more than $200 \mathrm{mi} \mathrm{h}^{-1}\left(320 \mathrm{~km} \mathrm{~h}^{-1}\right.$; NWS 2011). Over no less than 4 of those $6 \mathrm{mi}$, the tornado was rated EF5, the first EF5 tornado in Missouri since the Ruskin Heights tornado struck south of Kansas City in 1957. It also marks the first EF5 tornado on record in southwest Missouri 
(Turner and Hacker 2011). Near Duquesne Road the tornado was rated EF4 to EF3, and when it entered the rural areas it was rated as EF2 to EF1 (Fig. 1).

The 2011 Joplin tornado intensified remarkably quickly, changing from a mere funnel cloud into a violent tornado in fewer than 10 min (Mustain 2011). The initial touchdown occurred just west of Joplin at 1734 CDT and moved into the city at $1736 \mathrm{CDT}$. This provided approximately a 17 -min lead time for touchdown and a 19-min lead time before it entered Joplin (NWS 2011). The tornado's path narrowly missed downtown Joplin, but it destroyed four schools, including Joplin High School, and damaged six other schools, as well as several industrial buildings (Ryan 2011). The damage swath covered $7.44 \mathrm{mi}^{2}$, equivalent to nearly a quarter of Joplin, which is $31.54 \mathrm{mi}^{2}{ }^{2}$ According to the 2010 population census, 13547 people-27\% of the city's population-resided in the 500 census blocks directly affected by the tornado (U.S. Census Bureau 2010).

The Joplin tornado destroyed 4000 homes and damaged 3000 others, causing displacement of at least 9200 people. It destroyed 553 businesses of varying sizes and affected nearly 4000 jobs (Joplin Globe 2011a). ${ }^{3}$ One of the community's two hospitals, St. John's Regional Medical Center, was heavily damaged, which hampered initial response efforts. Several buildings of Freeman Hospital West, the other hospital in Joplin, also sustained damage. Additionally, the tornado destroyed Full Gospel Church, Harmony Heights Baptist Church, and Greenbriar Nursing Home. It caused an estimated \$3 billion in insured losses, not including uninsured damage to structures (Paul and Stimers 2011).

The Joplin tornado took the lives of 162 people, whether immediately or hours/days after the tornado. In hazard literature, the latter deaths are considered delayed deaths (i.e., deaths due to injuries sustained during the event). ${ }^{4}$ In addition, five people died from

\footnotetext{
${ }^{2}$ Damage area was initially reported as $2.81 \mathrm{mi}^{2}$; however, according to the FEMA GIS map, it was approximately $7.44 \mathrm{mi}^{2}$. The average tornado damage area in the United States is less than $1 \mathrm{mi}^{2}$ (Simmons and Sutter 2011).

${ }^{3}$ The number of homes and businesses damaged or destroyed differs not only over time, but also from one source to another. A six-page long report published by the City of Joplin on 5 April 2013 reports that the 2011 tornado destroyed and damaged 4000 and 3500 residential dwellings, respectively. The Jasper County GIS estimates damage or destruction of a total of 7608 structures, including 792 commercial structures, while the USACE claims a total of 8369 structures damaged or destroyed, including 321 commercial structures (Levitan 2011).

${ }^{4}$ Various sources report different fatality totals for the 2011 Joplin tornado. As of 1 November 2012, the SPC reported a death toll of 158 (SPC 2012).
}

a fungal infection linked to the tornado (Murphy 2011; Neblett Fanfair et al. 2012). It stands as the deadliest single tornado to hit the United States since 1950, surpassing the Flint, Michigan, tornado of 8 June 1953 that claimed 116 lives (Mustain 2011; NWS 2011). No single tornado from 1980 to 2010 has killed more than 40 people (Simmons and Sutter 2012). Over the last $30 \mathrm{yr}$, tornado fatalities in the United States have averaged around $55 \mathrm{yr}^{-1}$; the Joplin tornado alone caused nearly 3 times that average (Simmons and Sutter 2011). The 1925 Tri-State tornado, with a 291-mi path, killed 2.4 people per mile; the Joplin tornado caused 27 deaths per mile. Despite the record number of deaths, it is fortunate that, with the tornado on a Sunday, schools were empty and nearly 200000 commuters were home in the suburbs (Kayyem 2012).

\section{Tornado fatalities: An overview}

Tornado fatalities in the United States have been studied over time, by month, by time of day and the day of week, by state/region, by F scale or EF scale rating, by lead time, by place or location of death, by age and sex of the deceased, and so forth (e.g., Daley et al. 2005; Ashley 2007; Wurman et al. 2007; Simmons and Sutter 2008; Sutter and Simmons 2010; Simmons and Sutter 2011, 2012; Simmons et al. 2012). Simmons and Sutter (2011) have identified four major vulnerabilities for tornado casualties: tornadoes that occur overnight, tornados that occur during the fall/winter months, residence in a mobile home, and location in the United States (specifically, the southeastern part of the United States; see also Schmidlin et al. 2009; Chaney and Weaver 2010). Whether people are in their homes or driving, whether they are asleep or awake, and whether the tornado is visible or surrounded by rain are factors associated with the probability of death in a tornado (Wurman et al. 2007).

Studies (e.g., Curtis and Fagan 2013) also claim that wooden homes offer less protection than brick structures and that multiple-level home or apartment residents face a higher probability of death from tornadoes than single-family and one-level house residents. Old houses - those with walls not anchored to the foundationand houses without a basement are risk factors for high tornado mortality (Balluz et al. 2000). Studies (e.g., Balluz et al. 2000; Wurman et al. 2007) suggest that location of a tornado path is also an important determinant of deaths. If the path passes over highly populated areas, deaths are likely to be higher than if it passes over less populated areas. Tornado deaths also depend on the nature of tornado warnings and compliance with such warnings (Daley et al. 2005). If warnings are not issued in 
a timely manner, or warnings are not issued at all, the population at risk is unable to seek safety, which may contribute to higher instances of deaths (Balluz et al. 2000; Simmons and Sutter 2008).

Socioeconomic characteristics of residents are also important determinants of tornado mortality (Cutter et al. 2003). These characteristics dictate who receives hazard warnings and who does not comply with such warnings, and who owns a sturdy house and who does not (Paul and Stimers 2014). Because of their relevance to this study, tornado fatalities by EF scale rating and by place/location of death were of interest to this study. In general, the greater the intensity or magnitude of a tornado is, the higher the fatality potential (Paul 2011), although in absolute terms, more people have died as a result of F0 through F4 tornadoes because EF5 tornadoes occur much less often.

Using the National Weather Service (NWS) data for the period 1950-2007, Simmons and Sutter (2011) reported that the $1.2 \%$ of tornadoes rated F4 or F5 accounted for $62 \%$ of fatalities. By contrast, $78 \%$ of tornadoes were weak (rated F0 or F1) and accounted for only 5\% of fatalities. In terms of fatalities per tornado during the period 1950-2007, F0 killed 0.0011 per event, F1 killed 0.012 per event, F2 killed 0.061 per event, F3 killed 0.51 per event, F4 killed 3.65 per event, and F5 killed 16.27 per event. Fatalities per tornado differ by a factor of roughly 15000 when comparing F5 tornadoes with F0 tornadoes (Simmons and Sutter 2011). When the period extends to 2011, the lethality of F5 tornadoes does not change.

Another way to understand the lethality of F5 tornadoes is to express fatalities per killer tornado. Any tornado that kills at least one person is called a killer tornado. Of the nearly 55000 tornadoes that occurred since 1950 , only about $2.6 \%$ killed one or more persons (Simmons and Sutter 2011). Information presented in Table 1 suggests that from 2000 to 2011, only 299 of the 1158 tornado deaths were caused by EF5 tornadoes. This means nearly $26 \%$ of all tornado deaths during this period were caused by EF5 tornadoes. However, in relative terms, the most powerful EF5 tornadoes cause more deaths per event than tornadoes of lower magnitude. Between 2000 and 2011, EF5 tornadoes caused nearly 13 times more deaths per killer tornado than tornadoes of magnitudes EF4 and lower (Table 1). This clearly supports the contention that stronger tornadoes are more deadly than weak ones.

Available studies (e.g., Gruntfest 1987; Daley et al. 2005) suggest that the vulnerabilities and effects of natural disasters are not distributed evenly by gender and age. Using NWS records on tornado victims from 1996 to 2007, Simmons and Sutter (2011) claim that
TABLE 1. Tornado fatalities in the United States by magnitude, 2000-11 (SPC 2012).

\begin{tabular}{lccc}
\hline Magnitude & $\begin{array}{c}\text { Number of } \\
\text { fatalities }\end{array}$ & $\begin{array}{c}\text { Number of } \\
\text { killer tornadoes }\end{array}$ & $\begin{array}{c}\text { Number of } \\
\text { fatalities per } \\
\text { killer event }\end{array}$ \\
\hline EF5 & 299 & 8 & 37.38 \\
EF0 to EF4 & 859 & 294 & 2.92 \\
Total & 1,158 & 302 & 3.83 \\
\hline
\end{tabular}

fatalities are reasonably balanced between the sexes. They write that "[m]en were slightly more likely to be killed than women, at $51.2 \%$ of fatalities, even though women comprise almost $51 \%$ of the U.S. population" (Simmons and Sutter 2011, p. 61). Contrary to gender, Simmons and Sutter (2011) claim that tornado victims tend to be older than the U.S. population as a whole. Referring to the Spencer, South Dakota, 1998 tornado, Wurman et al. (2007) maintain that very elderly and very young are particularly vulnerable to tornadoes because they are slower to evacuate to safe locations. Because of partial or full hearing loss or living alone, many elderly may not have access to tornado warning. They also have a tendency to dismiss warnings in a cognitive process framed by situational factors (Schmidlin and King 1995).

The NWS records also provide information on the place of tornado fatalities since 1985 . When such information is analyzed for 1985-2012, slightly over $41 \%$ of tornado fatalities occurred in mobile homes, followed by nearly $34 \%$ in what the NWS describes as permanent homes (Fig. 2). Other locations for fatalities include about $10 \%$ in businesses (including hospitals, schools, stores, and churches), slightly over $8 \%$ in vehicles, and about $5 \%$ outdoors (www.spc.noaa.gov/climo/ torn/fataltorn.html). ${ }^{5}$ The percentage of fatalities in mobile homes compared to permanent homes is remarkable, because mobile homes accounted for only $7.6 \%$ of U.S. housing units in 2000 , and only $6.9 \%$ of the population lives in mobile homes (Simmons and Sutter 2011). This clearly suggests that residents of mobile homes face a more significant risk of death than residents of permanent homes (Brooks and Doswell 2002; Brown et al. 2002; Daley et al. 2005).

\section{Methods}

Fatality data used in this study were drawn from several secondary sources. The Jasper County Emergency

\footnotetext{
${ }^{5}$ There is some ambiguity in the SPC's categorizations of locations of tornado fatalities. For example, there is no direct reference to the business/commercial structures. Instead, it uses a category termed "permanent building/structure."
} 


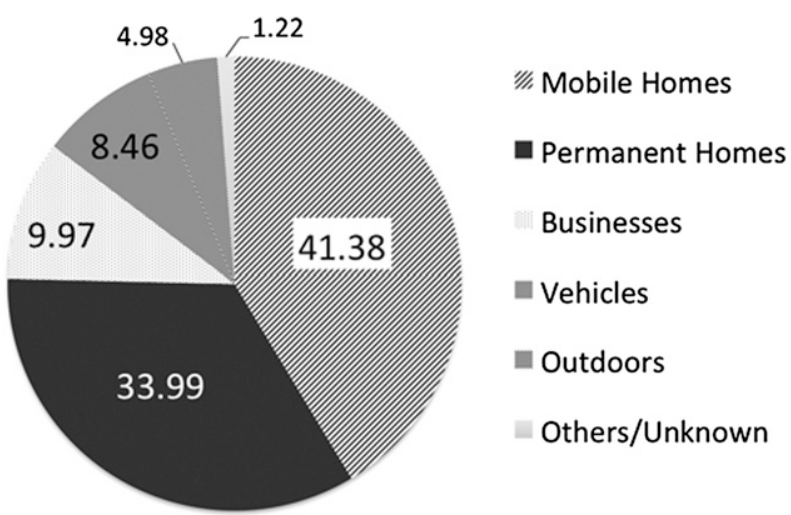

FIG. 2. Tornado deaths by location in the United States, 1985-2012 (Simmons and Sutter 2011; SPC 2012).

Operations Center provided a list of 126 victims and their date of birth. The Jasper County Coroner's Office and the Missouri Department of Public Safety also provided lists of the victims. Obituaries published over several issues of the Joplin Globe, the local daily newspaper, provided additional details about victims' backgrounds and other pertinent information. The Globe also compiled and published a separate list of the tornado victims. Alvarez (2011) contributed a chapter in Turner and Hacker's (2011) book that provided obituaries of 152 persons killed by the Joplin tornado. From these sources, we compiled a table with name, age, gender, date of death, and location of death of all tornado victims.

Before compiling the table, we compared the fatality data collected from secondary sources. In several cases, adjustments were made because home addresses or ages of the persons who died in the Joplin tornado differed slightly from one source to another. Other relevant information was collected from community leaders, local professionals, emergency officials, fire and law enforcement dispatchers, private contractors, and volunteers who helped clear debris to fully illuminate the circumstances of these deaths. We made four field visits and interacted with at least 50 people in order to collect information on how, where, and when people died.

Spatial data used in this study were collected from the City of Joplin's mapping division. These data were analyzed within a geographic information system (GIS) to show the distribution of deaths by tornado damage zones. Among the spatial data collected was a file from the Federal Emergency Management Agency (FEMA) of 8440 data points containing precise locations of damage in the tornado's path. Based on the extent of damage, FEMA divided the path into four damage zones: catastrophic, extensive, limited, and moderate
(Fig. 3). ${ }^{6}$ As instructed by FEMA, the U.S. Army Corps of Engineers (USACE) prepared the 2011 Joplin tornado damage map on 30 June 2011. Its staff collected damage data from the affected areas using GPS. With the help of GIS, USACE combined pre- and postdisaster areal photographs, parcel, property, and other relevant information from the city and county and prepared the damage zone map.

Using the information obtained from the city as well as from FEMA, tornado fatality totals were calculated to estimate death rates by the four damage zones. Additionally, damage zone size was estimated by calculating the square mileage of each zone within the track polygon layer as a whole based on kriging, a method widely used by GIS analysts in surface interpolation (Stein et al. 2002). This method was applied to the $z$ values of the point data to create the damage surface shown in Fig. 1. Kriging was chosen over inverse distance weighting (IDW), another commonly used interpolation procedure, because of a limitation in the IDW algorithm: IDW assumes that the spatial autocorrelation of point values in the area of interest change in a uniform manner, whereas kriging does not assign a universal distance power value, but rather estimates around individual points, producing a more robust surface (Oliver and Webster 1990). Population for the entire damage zone was calculated by intersecting 2010 census block data with the damage area polygon. The 2010 population of each affected census block was available from the NWS (U.S. Census Bureau 2012). Population estimates within each of the four damage zones were then calculated as a cross proportion of square mileage of 1) an individual zone over total square mileage of the damage zone to 2) population of an individual zone (the unknown in the cross-proportion equation) over population for the entire polygon (estimated as described above).

\section{Results}

\section{a. Deaths by damage zone}

Table 2 presents the distribution of Joplin tornado deaths by four damage zones (see also Fig. 3). This table shows that of the 162 deaths, $154(95.10 \%)$ occurred

\footnotetext{
${ }^{6}$ According to FEMA/USACE labeling, "moderate" is the zone with the least tornado damage. Though traditionally, "limited" should be zone with the least damage, we deliberately did not correct the damage zone labeling. In the catastrophic zone, most solid structures were destroyed, while destruction of some solid structures with most sustaining exterior damage occurred in the extensive damage zone.
} 




FIG. 3. Joplin tornado death by damage zone.

within these zones. Seven deaths took place in five other cities. With the exception of Kansas City, Missouri, all other cities are located in close proximity to Joplin. Two Joplin residents died at a Carthage, Missouri, nursing home (one suffered brain damage sustained during the storm, and the other suffered a spinal injury when a wall fell on the victim). One tornado victim died in Miami, Oklahoma, and another person in Duquesne, Missouri, from injuries sustained in the Joplin tornado (Joplin Globe 2011b).

Two Joplin residents died at a nursing home in Granby, Missouri, where they had been transferred following the destruction of Joplin's Meadows Healthcare
Center nursing home. Apparently, both died because of emotional trauma (Kennedy 2011). One 6-yr-old student of East Moreland School in Joplin died at Children's Mercy Hospital in Kansas City, Missouri, on May 23 because of injuries caused by the tornado (Kennedy 2011). The other victim, a police officer, was struck by lightning and killed while assisting with recovery and cleanup efforts the day after the tornado.

Although the overwhelming majority of the 162 deaths occurred on the day of the tornado, nearly $13 \%$ of the deaths occurred from injuries within hours after the event. Additionally, some of the out-of-town deaths occurred more than a month later (Paul and Stimers 2012).

TABLE 2. Deaths by damage zone.

\begin{tabular}{|c|c|c|c|c|c|}
\hline Zone & $\begin{array}{c}\text { Deaths } \\
\text { Number }(\%)\end{array}$ & $\begin{array}{c}\text { Estimated } 2010 \\
\text { population } \\
\text { Number }(\%)\end{array}$ & $\begin{array}{c}\text { Death rate } \\
\text { (per } 1000 \\
\text { population)* }\end{array}$ & $\begin{array}{c}\text { Area of } \\
\text { damage zone } \\
\text { (square miles) }\end{array}$ & $\begin{array}{l}\text { Death density } \\
\text { (deaths per } \\
\text { square mile) }\end{array}$ \\
\hline Catastrophic & $122(79)$ & $4716(35)$ & 21 & 2.59 & 47.10 \\
\hline Extensive & 17 (11) & 2039 (15) & 8 & 1.12 & 15.18 \\
\hline Limited & $10(7)$ & 3059 (22) & 3 & 1.68 & 5.95 \\
\hline Moderate & $5(3)$ & $3733(28)$ & 1 & 2.05 & 2.44 \\
\hline Total & $154(100)$ & $13547(100)$ & 4 & 7.44 & 20.70 \\
\hline
\end{tabular}

$*$ Chi-square $=137.717($ degrees of freedom $=3 ; p<0.0001)$. 
Generally, deaths after a specific disaster event from injuries are not included as a part of the total number of fatalities caused by that event, often described instead as "indirect," "secondary," or "peripheral" deaths. However, exclusion of such deaths is often discouraged because of incompleteness of such relatively unambiguous data (Kelman and Jonkman 2007). Accordingly, this study considered as tornado fatalities both immediate and delayed deaths (i.e., those who sustained injuries during the tornado and died later).

Table 2 shows that 122 of the 154 deaths (79\%) occurred in the central zone, which was labeled the catastrophic damage zone. The number of deaths systematically decreases with increasing distance from the central catastrophic zone. The second highest number of fatalities (17) occurred in the two extensive damage zones located on either side of the central zone. Ten deaths occurred in the limited zone and five in the moderate zone (Table 2). A similar spatial pattern is also evident when death rate is expressed per 1000 residents of the four zones (Table 2). Estimated 2010 populations in each of the four damage zones and death rate per 1000 residents are included in the table. The catastrophic zone accounted for $35 \%$ of the total population of all damaged zones, followed by $28 \%$ in the moderate, $22 \%$ in the limited, and $15 \%$ in the extensive zone. As expected, the catastrophic zone has the highest death rate (21 per 1000 persons), followed by extensive ( 8 per 1000 persons), limited ( 3 per 1000 persons), and moderate (1 per 1000 persons) zones. The death rate for the entire damage zone is calculated as 4 per 1000 persons.

Using the number of deaths by damage zone and the respective proportion of population, a goodness-of-fit chi-square test was performed. The chi-square value suggests that the damage zones differ significantly in number of deaths caused by the 2011 Joplin tornado. Deaths per square mile are also shown in Table 2. The density of deaths, expressed as deaths per square mile, by damage zone reveals a higher value in the catastrophic zone ( 47.1 deaths $\mathrm{mi}^{-2}$ ), followed by decreasing death density moving outward from the central zone; the extensive damage zone had a density value of 15.18 , the limited had a value of 5.95, and the moderate had a value of 2.44 deaths $\mathrm{mi}^{-2}$.

Information presented in Table 2 clearly supports the key hypothesis of this study that the number of tornado fatalities in Joplin differs by damage zone. In addition to absolute number of deaths, the table also presents death rates in terms of per 1000 residents and per square mile of damage zones. Despite variations in estimated population and area of damage zones, the number of deaths and death rates consistently decrease outward from the central zone. However, this finding should be treated
TABLE 3. Home location of Joplin tornado victims.

\begin{tabular}{lcc}
\hline \hline & Location & Number $(\%)$ \\
\hline Joplin & Within damage zone & $127(78.40)$ \\
& Outside damage zone & $11(6.79)$ \\
Neighboring communities & $24(14.81)$ \\
Total & $162(100.00)$ \\
\hline
\end{tabular}

with caution because not all of the 2011 Joplin tornado deaths occurred within the four damage zones.

Table 3 indicates that of all the deaths caused by the 22 May 2011 tornado, $138(85.19 \%)$ were residents of Joplin. Of these 138, 11 (7.97\%) actually lived outside the damage zones but at the time of the tornado were in one of the four damaged zones. Table 3 further shows that 24 tornado victims were residents of 14 neighboring communities: Fort Scott, Pittsburg, Altamont, Columbus, Galena, Carthage, Neosho, Goodman, Carl Junction, Duquesne, Web City, Granby, Pierce City, and Seneca (also see Fig. 4). The first five of these 13 cities are in Kansas, and the rest are in Missouri. Two rural residents of Jasper County and one rural resident of Newton County also died from the tornado. Both of these counties are in Missouri and are adjacent to one another (Fig. 4). All 24 out-of-town victims were in one of the four damaged zones when the tornado passed through.

The relatively high number of non-Joplin-resident deaths reflects Joplin's status as a major regional center. It lies near borders of Missouri, Kansas, Oklahoma, and Arkansas. Because the tornado occurred on a Sunday, many Joplin residents were away from their homes attending church or high school graduations, visiting friends, shopping, or dining out, among other activities. People came into Joplin that day from neighboring communities for similar reasons, including work. For example, the manager of Joplin's Home Depot, Dean Wells of Web City, Missouri, died during the tornado (Joplin Globe 2011c). Nonresidents also came to attend the Joplin High School graduation ceremony, which was held at the Leggett \& Platt Athletic Center on the campus of Missouri Southern State University. The Center itself was not in the damage path, but the high school was destroyed.

A considerable number of Joplin residents from outside the damage zone were visiting the homes of friends and relatives located in the damage zone; some died, and many others sustained injuries. The field survey also revealed that an unspecified number of residents left before tornado touch down, moving from within the damage zone to outside the damage zone, either to visit friends or to attend churches or the high school graduation. None of these individuals suffered injuries or 




FIG. 4. Home location of Joplin tornado victims. 
TABLE 4. Number of tornado fatalities per damage zone by victims gender and age.

\begin{tabular}{lrrrrr}
\hline \hline & Catastrophic & Extensive & Limited & Moderate & Total \\
\hline Gender & & & & & \\
Male & 56 & 10 & 7 & 3 & 76 \\
Female & 66 & 7 & 3 & 2 & 78 \\
Total & 122 & 17 & 10 & 5 & 154 \\
Age group & & & & & \\
0-17 & 9 & 2 & 1 & 0 & 12 \\
18-44 & 23 & 4 & 5 & 0 & 32 \\
$45-64$ & 46 & 5 & 1 & 1 & 53 \\
$\geq 65$ & 44 & 6 & 3 & 4 & 57 \\
Total & 122 & 17 & 10 & 5 & 154 \\
\hline
\end{tabular}

death. One respondent reported that he escaped death or injury only because he was visiting a friend, whose house was outside the tornado path; he was renting a house at 15th Street and Range Line Road and lived there with his landlord. Unfortunately, his landlord died when the house was demolished by the tornado.

\section{$b$. Deaths by gender and age of victims per damage zone}

Table 4 provides information on gender and age of tornado victims by the damage zone. The table shows that of the 154 deaths, 78 (50.65\%) were women and the remaining $76(49.35 \%)$ were male. Although slightly more females died than males, in reality, the Joplin tornado fatalities are considered to be reasonably balanced between the sexes because females accounted for $52.10 \%$ of the total population of Joplin in 2010 (U.S. Census Bureau 2010). Thus, the number of female deaths attributable to the 2011 Joplin tornado is proportional to the female population of Joplin. Calculated chi-square value $\left(\chi^{2}=3.124\right.$; degrees of freedom $=3$; $p=0.373$ ) also confirms that male and female fatality does not differ by damage zones.

Information presented in Table 4 shows that persons $65 \mathrm{yr}$ and older accounted for the highest numbermore than a third-of tornado fatalities in Joplin. According to the 2010 census, residents 65 and older represented only $14.8 \%$ of the total population of Joplin, but they experienced more than three times as many deaths as the total population of this cohort. Similarly, the 45-64 age cohort experienced 1.5 times as many deaths as compared to their share in the total population. This group represented $23 \%$ of the total population but accounted for $34 \%$ of the total fatalities. Consistent with this study, Curtis and Fagan (2013) also report that the number of elderly fatalities in Joplin was significantly higher than other cohorts. They died in care facilities, churches, residential dwellings, and apartment complexes.
The 2010 census also reported that persons younger than 18 accounted for nearly $30 \%$ of the total population of Joplin, but their share of total tornado deaths was only $7.79 \%$ (Table 4). Conversations with Joplin residents and others reveal that parents assumed considerable risk to their lives in order to save the lives of their children. The Joplin Globe published several such reports in the newspaper (Joplin Globe 2011a). Like the youngest age cohort, the second youngest age cohort (18-44) also experienced relatively fewer deaths compared to their share in the total population. They accounted for $36 \%$ of the total population, but experienced nearly $21 \%$ of the total tornado fatalities. Tornado deaths by age support the claim of Simmons and Sutter (2011) that elderly are most vulnerable to tornado death in the United States (see also Schmidlin and King 1995). Because many cells containing age group data in Table 4 have values less than 5, no chi-square test was performed.

Consistent with deaths by damage zone (Table 2), for both male and female Joplin tornado victims, the highest number of deaths occurred in the central or catastrophic damage zone. The number of deaths consistently decreases with increasing distance from the central zone. The second highest number of fatalities for both sexes occurred in the extensive zone (Table 4). A similar pattern of deaths is observed when age of the tornado victims is analyzed by the four damage zones. For all four age groups considered in this study, the highest number of deaths occurred in the central zone and the lowest number occurred in the outermost zone (Table 4). Although not presented in Table 4, when death rates per 1000 male and female or by age groups for each damage zone were calculated, the pattern is similar to the one described above: the rates consistently decrease from the catastrophic zone to the other three zones.

\section{c. Location of death}

Table 5 presents 2011 tornado fatality totals by location of death for the United States, the United States without Joplin, and for Joplin. These totals were reported by the Storm Prediction Center (SPC) on 15 October 2012. The table clearly shows remarkable differences in terms of proportion of tornado deaths by several locations among the United States, the United States without Joplin, and Joplin. These differences are particularly evident between the United States and Joplin. While mobile homes accounted for slightly over $20 \%$ of all tornado deaths in the United States in 2011, in Joplin, none occurred in mobile homes. According to the Joplin community profile, of a total 21362 housing units, 350 (2\%) were mobile homes in 2009 (City-Data. com 2011); this percentage is much lower than the national 
TABLE 5. Tornado fatalities by location of deaths, 2011 (SPC 2012).

\begin{tabular}{|c|c|c|c|}
\hline Location & $\begin{array}{c}\text { United } \\
\text { States } \\
\text { number }(\%)\end{array}$ & $\begin{array}{c}\text { United States } \\
\text { without } \\
\text { Joplin number }(\%)\end{array}$ & $\begin{array}{c}\text { Joplin } \\
\text { number (\%) }\end{array}$ \\
\hline Mobile home & $112(20.25)$ & $112(28.35)$ & - \\
\hline $\begin{array}{l}\text { Permanent } \\
\text { home }\end{array}$ & 229 (41.41) & $164(41.52)$ & $65(41.14)$ \\
\hline Vehicle & $34(6.15)$ & $19(4.81)$ & $15(9.50)$ \\
\hline Business & $92(16.63)$ & $26(6.58)$ & $66(41.77)$ \\
\hline Outside/open & $7(1.27)$ & $5(1.27)$ & $2(1.26)$ \\
\hline Other/unknown & 79 (14.29) & 69 (17.47) & $10(6.33)$ \\
\hline Total & $553(100.00)$ & $395(100.00)$ & $158(100.00)$ \\
\hline
\end{tabular}

percentage. Field surveys combined with a GIS analysis revealed that almost all of the mobile home units in Joplin were outside the tornado path (Paul and Stimers 2012).

It is worthwhile to mention that the proportion of deaths caused by tornadoes in the United States in 2011 defies past trends. Figure 2 clearly illustrates that over the past $27 \mathrm{yr}$, more tornado deaths have occurred in mobile homes than any other location tracked by the SPC. The number of violent tornadoes in 2011 explains why the proportion of deaths in mobile homes was relatively low and the proportion of deaths in permanent homes was relatively high (Simmons et al. 2012). ${ }^{7}$ Sutter and Simmons (2010) reported that more fatalities occur in mobile homes in less powerful tornadoes-those rated $\mathrm{EF} 1, \mathrm{EF} 2$, or $\mathrm{EF} 3$ on the $\mathrm{EF}$ scale - than fatalities overall. More specifically, EF1 and EF2 tornadoes are potentially lethal for residents of mobile homes. They observed no significant death toll difference between mobile and permanent home residents for EF4 and EF5 tornadoes (see also Simmons et al. 2012).

Among all locations listed in Table 5, permanent homes accounted for the highest proportion $(41 \%)$ of tornado deaths in the United States in 2011. In Joplin, for $41 \%$ of all deaths, permanent homes rank second in both absolute and relative terms. In both cases, the percentage of death in permanent homes is much higher than the corresponding percentage reported for the period 1985-2012 (Fig. 2). With the location of 79 fatalities still unknown, the contribution of deaths in permanent homes in the United States could change. As compared to the 1985-2012 period, relatively more deaths occurred in Joplin in permanent homes, largely because of the absence of basements and inadequate

\footnotetext{
${ }^{7}$ Six EF5 tornadoes occurred in 2011, compared to just two EF5 tornadoes nationally over the prior decade (Simmons and Sutter 2012).
}

structural conditions in housing units of the city (Paul and Stimers 2012).

According to a NWS (2011) assessment team report, many Joplin residents took shelter after receiving the tornado warnings in the most appropriate location (e.g., interior rooms or hallways, or crawl spaces) within their permanent homes. Unfortunately, a considerable number of them did not survive (NWS 2011). For example, Margaret Tutt, a 92-yr-old woman who had lived alone since 1952 in a single-story brick home on South Wall Avenue, followed a standard drill when she heard sirens. She grabbed a purse packed with a battery-operated radio, a flashlight, and medication for a breathing problem, and went into her interior bathroom. Her house was demolished and she died there (Younker and Kabel 2011).

Even though many residents waited to take action until the last seconds, the NOAA report claims that in many cases it was a life-saving measure. Belowground shelters (e.g., basements and/or crawlspaces) are not common in the Joplin area, and some people likely found themselves in situations that were not survivable in a tornado of this magnitude (EF5). It is unclear to what degree the lack of basements contributed to tornado mortality in Joplin (NWS 2011).

According to the Jasper County Assessor's Office, nearly $78 \%$ of houses in the county lack basements, due either to shallow bedrock geology or high water table (Ryan 2011). Joplin has fewer basements than Jasper County communities as a whole. Officials further reported that $28 \%$ of Joplin's new homes had basements as of 2009 compared with $38 \%$ two decades before. In addition to lack of basements, most of the houses in Joplin are relatively old; in 2009, the median house value in Joplin (\$93108) was 34\% below the Missouri state average of $\$ 139700$ (City-Data.com 2011). Older houses were constructed according to the standards of the time, which were far less stringent than today's more rigorous building codes. Many of these older houses are not secured to their foundation; some do not even have a foundation (Paul and Stimers 2011).

Both Table 5 and Fig. 2 show a striking contrast between the United States as a whole and Joplin in the proportion of tornado deaths in business structures. Nearly $17 \%$ of 2011 fatalities and $9.97 \%$ of $1985-2012$ fatalities occurred in such structures in the United States, but in Joplin, $42 \%$ of all deaths occurred in business structures. No other tornado has destroyed or damaged so many business facilities in the past. Although the Joplin tornado path barely missed the downtown area, it devastated Range Line Road, the hub of Joplin's economy (Turner and Hacker 2011). Many restaurants and retail stores are located along this road, and several 
TABLE 6. Number of tornado fatalities by location and damage zone (number of structures are drawn from USACE; Levitan 2011).

\begin{tabular}{|c|c|c|c|c|c|}
\hline Location & Catastrophic & Extensive & Limited & Moderate & Total \\
\hline \multicolumn{6}{|l|}{ Residential } \\
\hline Number of structure & 1,612 & 1,192 & 1,381 & 1,166 & 5,351 \\
\hline Number of death & 60 & 1 & 3 & 1 & 65 \\
\hline Death per 1000 people & 9.80 & 0.84 & 2.17 & 0.86 & 121.50 \\
\hline \multicolumn{6}{|l|}{ Commercial } \\
\hline Number of structure & 138 & 60 & 58 & 65 & 321 \\
\hline Number of death & 42 & 15 & 6 & 3 & 66 \\
\hline Death per 1000 people & 304.35 & 250.00 & 113.21 & 46.15 & 205.61 \\
\hline \multicolumn{6}{|l|}{ Others } \\
\hline Number of structure & 572 & 380 & 574 & 410 & 1,936 \\
\hline Number of death & 20 & 1 & 1 & 1 & 23 \\
\hline Death per 1000 people & 34.97 & 2.63 & 1.74 & 2.44 & 11.88 \\
\hline
\end{tabular}

fatalities occurred in those businesses. For example, the tornado killed two Pizza Hut employees and one in the AT\&T store-both businesses are on South Range Line Road (Joplin Globe 2011c; Zagier 2011). The tornado also inflicted damage on a Walgreens pharmacy, Academy Sports, Pizza by Stout, Sonic, Jiffy Lube, Wendy's, Payless Shoes, The Big Nickel, Aldi's, and the local Pepsi distribution plant (Turner and Hacker 2011).

Other business facilities in Joplin severely affected by the tornado included the 15th Street Walmart Supercenter, the Home Depot store, and several restaurants, all of which were flattened. Two walls of the Home Depot store collapsed in a domino effect after the tornado lifted the roof, killing seven people in the front of the store; fortunately, 28 people in the back of the store survived when the walls collapsed outwards. Three people died in the Walmart Supercenter, but 200 survived (Dennis 2011). Three Harmony Heights Baptist Church worshippers did not survive the Sunday afternoon twister. Fatalities were also reported from other churches.

At least 10 elderly residents died in the Greenbriar Nursing Home (Zagier 2011). Three people died at the Elks Lodge, which had been preparing for bingo night when the tornado struck. If this tornado had arrived two hours later, there would have been as many as 40 or 50 people in the lodge, and many of them likely would have been killed. Six people died in St. John's Regional Medical Center; five of those victims were patients on ventilators who died after the building lost power and a backup generator failed. The sixth fatality was a hospital visitor (Dennis 2011).

The proportion of tornado deaths occurring in vehicles was higher in Joplin than the nation as a whole (Table 5). Because the Joplin tornado occurred on Sunday afternoon, many people were in vehicles, returning to their homes from stores, restaurants, the Joplin High School graduation ceremony, or from out of town, explaining the relatively higher number of tornado deaths in vehicles. An almost equal proportion of people died outdoors both in the United States as a whole and in Joplin. The proportion of tornado deaths classified as other or unknown in the United States is more than double Joplin's proportion (Table 5).

\section{d. Location of deaths by damage zone}

Finally, the location of deaths is also analyzed by tornado damage zone. Unlike Table 5 or Fig. 2, where six different locations are considered, Table 6 uses only three types of locations: residential, commercial/business, and others. The last category includes persons who died outside of a structure, including the 24th and Main Street triage center, industrial structures, or inside a vehicle. Deaths in unknown locations are also included in this category.

Data presented in Table 6 suggest that most tornado deaths in Joplin occurred in buildings located in the catastrophic damage zone. This zone accounted for $30 \%$ of all residential structures, but $92 \%$ of all deaths occurred in this zone. The same is also true for commercial and other structures. Nearly $43 \%$ of all commercial structures were located in the catastrophic zone, but this zone accounted for nearly $64 \%$ of all deaths in such structures. Unlike residential and other structures, the extensive damage zone also experienced a relatively higher proportion of deaths in commercial structures. This zone accounted for nearly $19 \%$ of all commercial structures, but it experienced about $23 \%$ of all deaths occurring in commercial structures. This indicates that the business deaths were less concentrated in the catastrophic damage zone than the deaths in the residential structures. Catastrophic and extensive damage zones together accounted for nearly $87 \%$ of all deaths in commercial buildings-slightly over $5 \%$ below the proportion of residential deaths that occurred in the catastrophic 
zone. This, in turn, calls into question how well such structures protect their occupants. This is an important finding because business structures are generally considered relatively safe locations in comparison to other structure types. Prior to 2011 about $5 \%$ of all U.S. tornado deaths occurred in such structures (Simmons and Sutter 2011). In the past, no other single tornado damaged and/or destroyed as many commercial structures as the Joplin event. Tornadoes usually spend most or all of their lifetimes over sparsely and/or unpopulated areas (Wurman et al. 2007; Stimers 2011); only about $10 \%$ of all tornadoes pass through populated areas and almost all of these events miss commercial areas (Stimers 2011).

Information included in Table 6 generally supports, with few exceptions, the contention that both number of death and death rates per 1000 structures for residential, business, and others locations generally follow a decreasing trend from the catastrophic zone to outward zones. However, comparison of death rates per 1000 structures presented in Table 6 clearly highlights the business death aspect of the Joplin tornado death toll. Business location death rates are much higher than the residential location rates in all four damage zones. There are basically two reasons for this. The number of deaths caused by the Joplin tornado in business structures was far higher than the national annual average for the same type of location. The number of commercial/business structures (321) was much lower compared to the number of residential structures (5351). The differences in denominator also contributed to a large gap in tornado fatality rates between residential and business locations. We were unable to calculate the number of destroyed and damaged residential structures by the four tornado damage zones considered in this study. However, we assume that the death rates for destroyed residential structures would be higher than for damaged residential structures.

\section{Conclusions}

This study has analyzed the 2011 Joplin, Missouri, tornado fatalities by four damage zones. We found that the central zone (labeled as catastrophic) produced the most fatalities, while the remaining three zones (extensive, limited, and moderate, in order of decreasing intensity) generally showed a decreasing number of deaths. The rate of deaths per 1000 residents also decreased from the catastrophic zone outward, as did the density of deaths (deaths per square mile). This provides support for the working hypothesis that the number of deaths or death rate differs significantly by tornado damage zone. The analysis further suggests that the locations of Joplin's record number of deaths caused by the 2011 tornado were in striking contrast to national trends between 1985 and 2012, as well as to the locational pattern that emerged in 2011 for the United States as a whole, particularly for mobile homes and business facilities. In fact, the 2011 tornado season resulted in a death toll not seen in this country for decades. Fatalities in 2011 stand at 553, and the 500-fatality threshold had not been eclipsed since 1953, when 515 fatalities occurred (Simmons and Sutter 2012).

Although people died in many locations (e.g., churches, nursing homes, residential dwellings, hospital, and retail outlets), what truly stands out as exceptional about Joplin tornado is the business fatalities. This calls into question the protective ability of such structures. Many business structures in Joplin had designated safe areas, but those areas did not offer sufficient protection against an EF5 tornado. This finding shows an urgent need to add additional (and more effective) safety features to such buildings, which will reduce fatalities from future tornado events.

The second-highest number of deaths occurred in residential buildings. Given the soil conditions of Joplin, most notably the depth to bedrock, residents of the city should seriously consider alternatives to basements before they begin constructing new homes. One such alternative is public shelters that can withstand severe tornadoes. Such a shelter was built $20 \mathrm{mi}$ $(30 \mathrm{~km})$ southeast of Joplin in Seneca, Missouri, after a destructive tornado affected the community in 2008. Another alternative at the household level is a safe room, which costs between $\$ 6500$ and $\$ 8500$ to build (Spotts 2011). Not many Joplin residents can afford this and the Joplin city council did not make safe rooms a condition of rebuilding. Fortunately, a considerable number of homeowners had already built safe rooms either inside or outside their residential structures.

Another important finding of this study can help policy makers and public emergency management agencies to reduce elderly casualties. This study found a significantly high number of fatalities among the elderly population. One way to reduce their fatalities is through improving existing tornado warning dissemination system. Warnings should be disseminated in such a way that all elders are able to receive the intended warning in a timely manner. Public education should also be extended to them so that they can comply with tornado warnings (Paul and Stimers 2012, 2014).

Analyses of this study required different types of data collected from many secondary sources. One of the challenges was to use appropriate data for a particular analysis because several sources provided the same type of data but not the same numbers. Our field-experience-based 
knowledge of the study area and excellent cooperation from the city and county emergency officials proved very fruitful in this regard. Despite the fact that tornado fatalities are caused by interactions of many factors, evidence produced in this study clearly shows that the EF scale, which differs along as well as across tornado track, is an important determinant of tornado deaths.

\section{REFERENCES}

Alvarez, J., 2011: In memory of lives lost: Obituaries. 5:41: Stories from the Joplin Tornado, R. Turner and J. Hacker, Eds., Kansas City Star Books, 161-220.

Ashley, W. S., 2007: Spatial and temporal analysis of tornado fatalities in the United States: 1880-2005. Wea. Forecasting, 22, 1214-1228, doi:10.1175/2007WAF2007004.1.

Balluz, L., L. Schieve, T. Holmes, S. Kiezak, and J. Malilay, 2000: Predictors for people's response to a tornado warning: Arkansas, 1 March 1997. Disasters, 24, 71-77, doi:10.1111/1467-7717.00132.

Brooks, H. E., and C. A. Doswell III, 2002: Deaths in the 3 May 1999 Oklahoma City tornado from a historical perspective. Wea. Forecasting, 17, 354-361, doi:10.1175/1520-0434(2002)017<0354: DITMOC $>2.0 . \mathrm{CO} ; 2$.

Brown, S., P. Archer, E. Kruger, and S. Mallonee, 2002: Tornadorelated deaths and injuries in Oklahoma due to the 3 May 1999 tornadoes. Wea. Forecasting, 17, 343-353, doi:10.1175/ 1520-0434(2002)017<0343:TRDAII >2.0.CO;2.

Chaney, P. L., and G. S. Weaver, 2010: The vulnerability of mobile home residents in tornado disasters: The 2008 Super Tuesday tornado in Macon County, Tennessee. Wea. Climate Soc., 2, 190-199, doi:10.1175/2010WCAS1042.1.

City-Data.com, 2011: Joplin, Missouri. City-Data.com. [Available online at www.city-data.com/city/Joplin-Missouri.html.]

Curtis, A., and W. F. Fagan, 2013: Capturing damage assessment with a spatial video: An example of a building and street-scale analysis of tornado-related mortality in Joplin, Missouri, 2011. Ann. Assoc. Amer. Geogr., 103,1522-1538, doi:10.1080/ 00045608.2013.784098.

Cutter, S. L., B. J. Boruff, and W. L. Shirley, 2003: Social vulnerability to environmental hazards. Soc. Sci. Quart., 84, 242-261, doi:10.1111/1540-6237.8402002.

Daley, W. R., S. Brown, P. Archer, E. Kruger, F. Jordan, D. Batts, and S. Mallonee, 2005: Risk of tornado-related death and injury in Oklahoma, May 3, 1999. Amer. J. Epidemiol., 161, 1144-1150, doi:10.1093/aje/kwi142.

Dennis, A., 2011: Reporter's notebook with Emily Younker: Survivors' tales nothing short of miraculous. Joplin Globe, 24 June. [Available online at http://www.joplinglobe.com/ tornado miracles/x1443109527/Reporters-notebook-video-withEmily-Younker-Survivors-tales-nothing-short-of-miraculous.]

Gruntfest, E., 1987: Warning dissemination and response with short led-times. Flood Hazard Management: British and International Perspective, J. Handmer, Ed., Geo Books, 191202.

Joplin Globe, 2011a: Official: 4,000 jobs affected: Many businesses hoping to rebuild. Joplin Globe, 27 May.

_ 2011b: Sunday's tornado upgraded to EF-5. Joplin Globe, 25 May. [Available online at http://www.joplinglobe.com/local/ x108199255/Sundays-tornado-upgraded-to-EF-5.]

_ 2011c: Local authorities fear death toll could eclipse 100. Joplin Globe, 23 May. [Available online at http://www.
joplinglobe.com/local/x433426155/Widespread-damage-reportedafter-tornado/print.]

Kayyem, J., 2012: The 'Joplin effect': The best of democracy and the best of community helped heal the city. Boston Globe, 24 May. [Available online at www.bostonglobe.com/opinion/2012/05/24/ the-joplin-effect/SxylpZvUwFPR1MxF36CdsI/story.html.]

Kelman, I., and S. N. Jonkman, 2007: Disaster deaths research challenges. Proc. Hazards and Disasters Researchers Meeting, Boulder, CO, Natural Hazards Center, University of Colorado Boulder, 18-21. [Available online at http://www.colorado.edu/ hazards/workshop/hdrm_proceedings.pdf.]

Kennedy, W., 2011: Death tally up again; President, governor to speak at observance. Joplin Globe, 28 May. [Available online at http://www.joplinglobe.com/local/x564433457/Death-tallyup-again-president-governor-to-speak-at-observance.]

Levitan, A. L., 2011: May 22, 2011 Joplin, MO tornado study: Draft study plan and research overview. National Institute of Standards and Technology, $56 \mathrm{pp}$.

Lyons, W. A., 1997: The Handy Weather Answer Book. Visible Ink Press, $397 \mathrm{pp}$.

Murphy, K., 2011: Five deaths from Joplin tornado linked to fungal infection. Kansas City Star, 30 July. [Available online at http://www.reuters.com/article/2011/07/30/us-tornado-deathsidUSTRE76T1DT20110730.]

Mustain, A., 2011: 2011 tornado death toll is worst since 1953. LiveScience. [Available online at http://www.livescience.com/ 14294-2011-tornado-death-toll-worst-1953.html.]

Neblett Fanfair, R., and Coauthors, 2012: Necrotizing cutaneous mucormycosis after a tornado in Joplin, Missouri, in 2011. N. Engl. J. Med., 367, 2214-2225, doi:10.1056/NEJMoa1204781.

NWS, 2011: NWS Central Region service assessment: Joplin, Missouri, tornado. National Weather Service Service Assessment, 35 pp. [Available online at www.nws.noaa.gov/om/ assessments/pdfs/Joplin_tornado.pdf.]

Oliver, M. A., and R. Webster, 1990: Kriging: A method of interpolation for geographical information systems. Int. J. Geogr. Info. Syst., 4, 313-332, doi:10.1080/02693799008941549.

Paul, B. K., 2011: Environmental Hazards and Disasters: Contexts, Perspectives and Management. Wiley-Blackwell, $322 \mathrm{pp}$.

- and M. J. Stimers, 2011: Tornado warnings and tornado fatalities: The case of May 22, 2011 tornado in Joplin, Missouri. Quick Response Research Rep. 226, Hazards Center, University of Colorado Boulder, Boulder, CO, 33 pp. [Available online at www. colorado.edu/hazards/research/qr/submitted/paul_2011.pdf.]

- and — 2012: Exploring probable reasons for record fatalities: The case of 2011 Joplin, Missouri, tornado. Nat. Hazards, 64, 1511-1526, doi:10.1007/s11069-012-0313-3.

—, and — 2014: Predictors for survivor responses to the 2011 Joplin, MO, USA, tornado. Disasters, in press.

Ryan, K., 2011: Joplin school district looks for way forward. Joplin Globe, 24 May. [Available online at http://www.joplinglobe. com/local/x1439575311/Joplin-School-District-looks-for-wayforward.]

Schmidlin, T. W., and P. S. King, 1995: Risk factors for death in the 27 March 1994 Georgia and Alabama tornadoes. Disasters, 19, 170-177, doi:10.1111/j.1467-7717.1995.tb00367.x.

— B. Hammer, Y. Ono, and P. S. King, 2009: Tornado shelterseeking behavior and tornado shelter options among mobile home residents in the United States. Nat. Hazards, 48, 191201, doi:10.1007/s11069-008-9257-z.

Simmons, K. M., and D. Sutter, 2008: Tornado warnings, lead times and tornado casualties: An empirical investigation. Wea. Forecasting, 23, 246-258, doi:10.1175/2007WAF2006027.1. 
, and - 2011: Economic and Societal Impacts of Tornadoes. Amer. Meteor. Soc., 282 pp.

and - 2012: Deadly Season: Analysis of the 2011 Tornado Outbreaks. Amer. Meteor. Soc., 103 pp.

- _ and R. Pielke, 2012: Blown away: Monetary and human impacts of the 2011 U.S. tornadoes. Extreme Events and Insurance: 2011 Annus Horribilis, C. Courbage and W. R. Stahel, Eds., Geneva Association for Risk and Insurance Economics, 107-120.

SPC, 2012: Annual U.S. killer tornado statistics. Storm Prediction Center, National Weather Service. [Available online at www. spc.noaa.gov/climo/torn/fataltorn.html.]

Spotts, P., 2011: Rebuilding after tornadoes: Two designs that could save lives in another storm. Christian Science Monitor, 26 May. [Available online at http://www.csmonitor.com/USA/ 2011/0526/Rebuilding-after-tornadoes-two-designs-that-couldsave-lives-in-another-storm.]

Stein, A., F. van der Meer, and B. Gorte, Eds., 2002: Spatial Statistics for Remote Sensing. Springer, 325 pp.

Stimers, M. J., 2011: A categorization scheme for understanding tornado events from the human perspective. Ph.D. dissertation, Department of Geography, Kansas State University, $213 \mathrm{pp}$. [Available online at http://krex.k-state.edu/ dspace/bitstream/handle/2097/8531/MitchelStimers2011. pdf? sequence $=1$.]
Suckling, P. W., and W. S. Ashley, 2006: Spatial and temporal characteristics of tornado path direction. Prof. Geogr., 58, 20 38, doi:10.1111/j.1467-9272.2006.00509.x.

Sutter, D., and K. M. Simmons, 2010: Tornado fatalities and mobile homes in the United States. Nat. Hazards, 53, 125-137, doi:10.1007/s11069-009-9416-x.

Turner, R., and J. Hacker, 2011: 5:41: Stories from the Joplin Tornado. Randy Turner, 228 pp.

U.S. Census Bureau, 2010: Joplin, Missouri quick facts. [Available online at http://quickfacts.census.gov/qfd/states/29/2937592.html.] 2012: Census data \& emergency preparedness: 2011 tornadoes. U.S. Census Bureau. [Available online at www.census. gov/newsroom/emergencies/2011_tornadoes.html.]

Wurman, J., C. Alexander, P. Robinson, and Y. Richardson, 2007: Low-level winds in tornadoes and potential catastrophic tornado impacts in urban areas. Bull. Amer. Meteor. Soc., 88, 3146, doi:10.1175/BAMS-88-1-31.

Younker, E., and M. Kabel, 2011: Most tornado fatalities occurred where people lived. Joplin Globe, 16 June. [Available online at http://www.joplinglobe.com/local/x1625119189/Mosttornado-fatalities-occurred-where-people-lived.]

Zagier, A. S., 2011: Joplin tornado: Some died while saving others Huffington Post, 4 June. [Available online at http://www. huffingtonpost.com/2011/06/04/joplin-tornado-death_n_871424. html.] 